\title{
Association between Written School Nutrition Wellness Policies and the Observed Nutrition Environment within the Elementary Schools
}

\author{
Shadai Martin, PhD RDN \\ Department of Family \& Consumer Sciences \\ Dept. 3470 Box 30003 \\ New Mexico State University \\ Las Cruces, NM 88003 \\ Jessica Meendering, PhD \\ Department of Health and Nutritional Sciences \\ SWG405, Box 2275A \\ South Dakota State University \\ Brookings, SD, 57007 \\ Lacey McCormack, PhD, RDN \\ Department of Health and Nutritional Sciences \\ SWG 415 Box 2275A \\ South Dakota State University \\ Brookings, SD 57007
}

\begin{abstract}
Background: Studies have demonstrated that written school wellness policies (SWPs) exist, but policies lack comprehensiveness and vary widely in strength of the language used to address mandated components. SWPs should support creating a healthy nutrition environment, however, it is unclear the extent to which they do. The aim of this study was to examine the association between overall quality (strength and comprehensiveness) of written SWPs and the observed physical, situational and policy nutrition environment and specific areas of interest within Midwestern elementary schools.

Methods: Twenty-six schools were visited during the 2017-2018 academic year. At each school, SPAN-ET was used to assess the physical, situational and policy environment within the school. Schools were categorized as 'poor', 'fair', 'good' and 'best' in each nutrition environment section based on the number of criteria met within specific areas of interest. Written SWPs were scored by two trained researchers, using WellSAT 2.0, prior to the onsite school visit, and strength and comprehensiveness of written SWPs were determined.

Results: Strength scores for the nutrition standards section of written SWPs were positively correlated with scores for the observed garden features area of interest $(r=.55, p<.01)$ and comprehensiveness scores for the nutrition education section of written SWPs were negatively correlated with scores for the observed school meals area of interest $(r=-.53, p<.05)$. Mean written SWP nutrition section scores did not vary across observed physical, situational or policy nutrition environment scores, or overall observed nutrition environment score.

Conclusion: Examining written SWPs together with the observed school environment can help to identify gaps between how policies are written and how they are being implemented within schools. This information has the potential to shape policy development, implementation and in turn, the school nutrition environment.
\end{abstract}

\section{Introduction}

During the 2006-2007 school year, all districts were required to establish a local school wellness policy (SWP). In 2010, Congress passed the Healthy, Hunger-Free Kids Act of 2010 and added new provisions for local SWPs. related to implementation, evaluation and publicly reporting on progress of local SWPs. Local education agencies were required to begin developing a revised SWP during the 2016-2017 school year, with full compliance with all the requirements being adhered to by June of 2017 (USDA 2017). Local education agencies are supposed to evaluate their wellness policy once every three years, with results being made available to the public (USDA 2017). Although local education agencies are required to create SWPs and meet the school meal nutrition requirements in order to receive federally subsidized reimbursements, little evaluation of the effect of these policies on students and student health has been conducted (Methos 2007, Chan 2014). 
Studies have demonstrated that written SWPs exist, but policies lack comprehensiveness and vary widely in strength of the language used to address mandated components (Chan 2014, Hoxie-Setterstrom 2011, Lox 2016, Lucarelli 2015, Meendering 2016). While comprehensiveness and strength of written SWPs improved in the years following the 20062007 mandate by Congress, they remain highly inconsistent and weak overall. Prior to the federal mandate, fewer than half of all U.S. school districts adopted policies to promote healthy eating and physical activity but after the mandate, nearly all schools had adopted a policy of some sort. However, relatively little has been written about policy implementation and evaluation (Holland 2016). There are evaluation tools that allow researchers, schools and school districts to determine the strength and comprehensiveness of written SWPs, but in policies, little research exists measuring the implementation of policies at the school level (Chan 2014, Hoxie-Setterstrom2011, Lox 2016, Lucarelli 2015). There is a need to identify and address factors involved in the successful implementation of SWPs, looking at schools in the larger context of their communities as highlighted by these studies (Phillips 2012, Snelling 2017, Lox 2016, Chaven 2017). A link exists between poor nutrition, obesity and chronic disease in youth (Kelsey 2014). There has been increasing attention geared towards the school being an ideal setting for promoting nutritious eating practices, but nutritious foods need to be available. Nutrition education should also be a key component of the curriculum and a key component of the physical environment (Price 2017, Rubio 2017). The school nutrition environment can provide students the opportunity to learn about and practice healthy eating through available foods and beverages, nutrition education and messages about food in the cafeteria and throughout the school campus. A healthy school nutrition environment can make it easier for students to make healthy choices. Assessing the school nutrition environment identifies opportunities for improvement and begins a planning process for making schools even healthier.

Written SWPs and the implementation of those policies have the potential to improve the school nutrition environment and in turn improve students' physical health and academic achievements. Policies should support creating a healthy nutrition environment, but it is unknown if they do. Therefore, the aim of this study was to examine the association between overall quality (strength and comprehensiveness) of written SWPs and the observed physical, situational and policy nutrition environment and specific areas of interest within Midwestern elementary schools.

\section{Methods}

\section{School Recruitment}

A list of school districts within a Midwest state was obtained from the Department of Education website. Every elementary school superintendent and principal was contacted by the Department of Education via a recruitment email. If interested, schools were encouraged to complete a recruitment questionnaire. As part of this electronic questionnaire, principals attached their current SWP and staff contact information to arrange an onsite visit with trained study staff. One hundred and ten school elementary schools were contacted; a response was received from twenty-nine schools. Twenty-six schools were visited during the fall of 2017 and spring of 2018. Schools missing data were excluded from analyses $(\mathrm{n}=1)$ and ultimately 25 schools were included in analyses. All protocols and procedures were approved by the South Dakota State University Institutional Review Board.

\section{Assessments}

To quantify the observed school environment, School Physical Activity and Nutrition Environment Tool (SPAN-ET) was used to assess the school nutrition and physical activity environment (Osu 2018). The SPAN-ET tool serves to fill the gap between extension research and educator's ability to understand the interplay between attributes of students and schools and the effect on students' behavioral choice and learning. Completing SPAN-ET involved several methods of data collection including face-to-face and/or telephone interviews with key informants, on-site direct observations, and content review of various forms of documentation. Forms of documentation included: written and/or published districtand school-level wellness policies, nutrition and school meal policies and guidelines, school meals menus, and playground rules and regulations. Two trained staff conducted SPAN-ET independently and came together to discuss and resolve discrepancies. SPAN-ET assigns section scores to the physical, situational and policy nutrition environments within the school. To determine these scores, multiple criteria within specific areas of interest are observed and evaluated; points are given for fully meeting criteria. For the present study, nutrition areas of interest were used. Nutrition areas of interest included: 1) cafeteria/meal service and garden features area of interest scores from the physical environment section; 2) school meals, food and beverage habits, food and beverage practices, drinking water, cafeteria atmosphere and before/after school extracurricular programs areas of interest scores from the situational environment section; 3) nutrition and wellness policy, nutrition and wellness committee and health and nutrition education areas of interest scores from the policy environment. Ultimately, scores from each area of interest make up the physical, situational and policy nutrition environment section scores. These scores can be summed to determine an overall school nutrition environment score. 
Mean scores for each area of interest within the SPAN-ET were calculated by taking the number of criteria met divided by the total number of criteria within the area of interest and multiplying by 100 . This scaled scores between $0-100$ which was the same range used for WellSAT scores. Additionally, numerical scores were grouped into 4 categories based on number of criteria met: poor $(\leq 25 \%)$, fair $(26 \%$ to $\leq 50 \%)$, good $(51 \%$ to $\leq 75 \%)$ and best $(>76 \%)$.

To quantify the strength and comprehensiveness of written SWPs, the WellSAT 2.0 was completed separately by two trained staff prior to the onsite visit (Uconn 2018). Using the WellSAT 2.0, written SWPs are evaluated based on the degree to which they address 78 policy items categorized into six sections. For each of the 78 policy items, SWP statements were rated " 0 ," "1," or " 2 ," based on an explanation of the item and examples of "1" and "2" statements. Strength and comprehensiveness scores are calculated for each section as well as for the overall SWP; scores ranged from 0-100. For this study, the sections of the SWP that encompassed nutrition-focused policies were used. The sections included were: 1) nutrition education (NE); 2) standards for USDA child nutrition programs and school meals (SM); and 3) nutrition standards for competitive and other foods and beverages (NS).

\section{Statistical Analysis}

Data were analyzed using Stata Statistical Software: Release 15 (StataCorp 2017). Pairwise correlations were used to determine if individual areas of interest scores within the observed nutrition environment sections of SPAN-ET were significantly associated with scores from the nutrition sections of the written SWP. One-way ANOVA was used to determine if mean nutrition section scores from written SWPs differed across categorical scores of SPAN-ETs physical, situational and policy nutrition environment sections as well as overall nutrition environment score.

\section{Results}

Mean scores for each observed nutrition area of interest within the physical, situational and policy environments of schools are presented in Table 1 along with frequency of categorical scoring. All schools (100\%) were categorized as 'Best' for the 'drinking water' area of interest. Most schools scored within the best category for the cafeteria/meal service area of interest (96\%) and also 'school meals' area of interest (83\%). Many schools $(96 \%)$ were categorized as 'poor' for the 'garden features' area of interest and for the 'nutrition and wellness committee' areas of interest $(60 \%)$.

Table 1. Mean scores determined by criteria met for each nutrition area of interest within the physical, situational and policy environment sections of SPAN-ET, along with and frequency of categorical scoring among all schools within the Physical, Situational and Policy Environment sections of SPAN-ET ( $\mathrm{n}=25)$.

\begin{tabular}{|r|c|c|c|c|c|}
\hline & Mean (range) & Poor & Fair & Good & Best \\
\hline Area of Interest (total criteria) & \multicolumn{5}{|l|}{} \\
\hline Cafeteria/Meal Service (5) & $93.9(60-100)$ & - & - & $4 \%$ & $96 \%$ \\
\hline Garden Features (2) & $2(0-50)$ & $96 \%$ & $4 \%$ & - & - \\
\hline School Meals (9) & $82.1(66.7-100)$ & - & - & $17 \%$ & $83 \%$ \\
\hline Food and Beverage Habits (7) & $47(28.6-71.4)$ & $4 \%$ & $60 \%$ & $36 \%$ & - \\
\hline Food and Beverage Practice (5) & $53.6(20-100)$ & $16 \%$ & $32 \%$ & $28 \%$ & $24 \%$ \\
\hline Drinking Water (8) & $98(87.5-100)$ & & - & & $100 \%$ \\
\hline Cafeteria Atmosphere (10) & $90(70-100)$ & - & - & $4 \%$ & $96 \%$ \\
\hline Butrition and Wellness Policy (15) & $55.5(40-73.3)$ & - & $32 \%$ & $68 \%$ & - \\
\hline Nutrition and Wellness Committee (5) & $36.5(0-100)$ & $60 \%$ & $4 \%$ & $16 \%$ & $20 \%$ \\
\hline Health and Nutrition Education (8) & $52(12.5-100)$ & $20 \%$ & $40 \%$ & $24 \%$ & $16 \%$ \\
\hline
\end{tabular}


Correlations between each observed nutrition area of interest score and each nutrition section score from the written SWP are presented in Table 2. There was a significant, SPAN-ET assigns section scores to the physical, situational and policy nutrition environments within the school. To determine these scores, multiple criteria within specific areas of interest are observed and evaluated; points are given for fully meeting criteria. For the present study, nutrition areas of interest were used. Nutrition areas of interest included: 1) cafeteria/meal service and garden features area of interest scores from the physical environment section; 2) school meals, food and beverage habits, food and beverage practices, drinking water, cafeteria atmosphere and before/after school extracurricular programs areas of interest scores from the situational environment section; 3) nutrition and wellness policy, nutrition and wellness committee and health and nutrition education areas of interest scores from the policy environment. Ultimately, scores from each area of interest make up the physical, situational and policy nutrition environment section scores. These scores can be summed to determine an overall school nutrition environment score. Mean scores for each area of interest within the SPAN-ET were calculated by taking the number of criteria met divided by the total number of criteria within the area of interest and multiplying by 100 . This scaled scores between 0-100 which was the same range used for WellSAT scores. Additionally, numerical scores were grouped into 4 categories based on number of criteria met: poor $(\leq 25 \%)$, fair $(26 \%$ to $\leq 50 \%)$, good $(51 \%$ to $\leq 75 \%)$ and best $(>76 \%)$.

Table 2. Correlation between SPAN-ET nutrition area of interest and WellSAT section score.

\begin{tabular}{|c|c|c|c|c|c|c|c|c|}
\hline & $\begin{array}{l}\text { NS } \\
\text { Stren } \\
\text { gth }\end{array}$ & $\begin{array}{c}\text { TS } \\
\text { Com } \\
p\end{array}$ & $\begin{array}{c}\text { SMI } \\
\text { Streng } \\
\text { th }\end{array}$ & $\begin{array}{c}\text { SMI } \\
\text { Com } \\
p\end{array}$ & $\begin{array}{c}\text { PEE } \\
\text { Streng } \\
\text { th }\end{array}$ & $\begin{array}{c}\text { RE } \\
\text { Com } \\
\mathbf{p}\end{array}$ & $\begin{array}{c}\text { Oweral } \\
\text { Strengt } \\
\text { h }\end{array}$ & $\begin{array}{c}\text { Overpl } \\
1 \\
\text { Comp }\end{array}$ \\
\hline \multicolumn{9}{|l|}{ Area of Interest (total criteria) } \\
\hline Cafereriadveal Service (S) & 11 & -13 & -01 & .11 & 23 & 27 & .13 & .16 \\
\hline Garden Features $(2)$ & $55^{+*}$ & 38 & .11 & 01 & .05 & -17 & 26 & 34 \\
\hline Schooil Meals og & -35 & -.27 & -15 & -21 & -34 & $-53^{-2}$ & -.39 &.$- .3 \mathrm{~B}$ \\
\hline Food and Beverage Habirs $(7)$ & -15 & -.16 & -12 & -.07 & -34 & -.17 & -.29 & -.22 \\
\hline Food and Eleverage Practice (S) & .05 & .02 & -11 & 100 & -14 & -11 & 1003 & .07 \\
\hline Drünking Wacer $(\mathrm{B})$ & .03 & -.12 & -13 & -27 & -10 & -0013 & -11 & -.11 \\
\hline Cafeteria Afmosphere 100 & -09 & .07 & -101 & -13 & -13 & -11. & .05 & -14 \\
\hline $\begin{array}{l}\text { Before/After School } \\
\text { Exracurricular Programs } 67\end{array}$ & -32 & -12 & -18 & -20 & -21 & -.25 & -.30 & -.27 \\
\hline $\begin{array}{l}\text { Whutrition and Wellness Polby } \\
\text { (15) }\end{array}$ & -22 & $-.2 \mathrm{~B}$ & -23 & -32 & -16 & .09 & -.16 &.- .14 \\
\hline $\begin{array}{r}\text { Wurtition and Wellnes: } \\
\text { Committee (5) }\end{array}$ & .05 & -.02 & .05 & -12 & -13 & -13 & 104 & .07 \\
\hline $\begin{array}{l}\text { Health and Wurrition Education } \\
\text { (B) }\end{array}$ & -30 & -.24 & -15 & -.03 & -25 & -.08 & -26 & -.19 \\
\hline
\end{tabular}

NS - mutrition standands for conperitive foods and beverages; SMI- school meals; NE - nurrition

education- Comp - conmprehensiveness

To quantify the strength and comprehensiveness of written SWPs, the WellSAT 2.0 was completed separately by two trained staff prior to the onsite visit (Uconn 2018). Using the WellSAT 2.0, written SWPs are evaluated based on the degree to which they address 78 policy items categorized into six sections. For each of the 78 policy items, SWP statements were rated " 0 ," "1," or " 2 ," based on an explanation of the item and examples of "1" and "2" statements. Strength and comprehensiveness scores are calculated for each section as well as for the overall positive correlation between written SWP nutrition standards for competitive foods and beverages section strength and the observed garden features area of interest $(\mathrm{r}=.55, \mathrm{p}<.01)$. Additionally, there was a significant negative correlation between written SWP nutrition education section comprehensiveness and the observed school meals area of interest $(r=-.53, p<.05)$. No other significant correlations between the quality of written SWP nutrition sections and the observed nutrition areas of interest were seen. Mean WellSAT section scores for strength and comprehensiveness scores across the physical, situational and policy nutrition environments scores are presented in Table 3. 
There were no significant differences in scores for written SWP sections across the categorical scores of the observed nutrition environments. Likewise, there were no significant differences in scores for written SWP sections across the categorical score of the overall observed nutrition environment (Table 4).

Table 3. Mean $( \pm$ SE) WellSAT nutrition section scores across SPAN-ET physical, situational and policy nutrition environment section score categories.

\begin{tabular}{|c|c|c|c|c|c|}
\hline & \multicolumn{4}{|c|}{ SFAN-ET Physical Nutrition Euvironment } & \multirow[b]{2}{*}{ P-wahe } \\
\hline WeIISAT & Poor & Faü & Good & Best & \\
\hline WS Strength & - & 0 & $20.7=5.5$ & 82 & 61 \\
\hline BNS Comy & - & II & $40.6=7.5$ & 9I & .55 \\
\hline SMI Strength & - & 14 & $262=5.0$ & 36 & 95 \\
\hline SN ComP & - & 21 & $40=5.4$ & 43 & $9 \mathrm{gB}$ \\
\hline ME Strength & - & 0 & $37.1=7.5$ & 43 & 28 \\
\hline NE CanP & - & 57 & $\mathrm{BI} \pm 5.9$ & 100 & 22 \\
\hline Overall Strength & - & 2 & 24.4 & 48 & .55 \\
\hline \multirow[t]{2}{*}{ Overall Comprehensiveness } & - & 23 & $459=5.1$ & 80 & -45 \\
\hline & \multicolumn{4}{|c|}{$\begin{array}{c}\text { SPAN-ET' Situational Nutrition } \\
\text { Environment }\end{array}$} & \\
\hline WS Strength. & - & - & $312=7.6$ & $13.9 \pm 3.4$ & .07 \\
\hline NS Camp & - & - & $48.8=9.0$ & $339=63$ & 22 \\
\hline SM Strength & - & - & $23.6=5.7$ & $30.1=4.7$ & 39 \\
\hline SM Cany & - & - & $37.9=6.4$ & $448+5.8$ & 44 \\
\hline WE Strength & - & - & $343=0.8$ & $3 B \leq=8.3$ & -75 \\
\hline NE COUM & - & - & $75 . \mathrm{B}=\mathrm{s} .3$ & $802 \pm 8.3$ & 71 \\
\hline Overall Strength & - & - & $189=4.1$ & $31=6.0$ & .13 \\
\hline \multirow[t]{2}{*}{ Overall Comprehensiveness } & - & - & $39.8=4.3$ & $52.4 \pm 6.8$ & .16 \\
\hline & \multicolumn{4}{|c|}{ SPAN-EI Policy Nutrition Environment } & \\
\hline
\end{tabular}

\begin{tabular}{|c|c|c|c|c|c|}
\hline NSS Strength & 36.0 & $27.8 \pm 8.0$ & $16.4=3.7$ & $\overline{-}$ & $4 \mathrm{~B}$ \\
\hline MS Coup & 45.0 & $45.6 \pm 9.4$ & $372=6.9$ & $\overline{-}$ & 80 \\
\hline SMI Strength & 29 & $28.4 \pm 5.5$ & $25.4=5.4$ & - & 93 \\
\hline SM ComP & 43 & $43.6 \pm 6.4$ & $39.6=6.0$ & $\overline{-}$ & $8 B$ \\
\hline NE Strength & 43 & $36.2 \pm 8.9$ & $36.6=9.9$ & - & 98 \\
\hline NE Coum & BE & SOZDEB.S & $747=8.2$ & - & $\mathrm{gB}$ \\
\hline Overall Strength & 24 & $28.5 \pm 6.4$ & $21.9=4.3$ & - & .74 \\
\hline Owemill Comprehensiveness & 42 & $49.9 \pm 7.2$ & $43 \_1=4.5$ & - & 76 \\
\hline
\end{tabular}

P-wahe deternined using one-way AWOWA

NS - mutrition standards for comperitive foods and beverages: SMI- school meals; NE - nutrition education: Comp - comprehensiveness 
Table 4. Mean $( \pm$ SE) WellSAT nutrition section scores across all SPAN-ET overall nutrition environment section score categories.

\begin{tabular}{|c|c|c|c|c|c|}
\hline \multirow[b]{2}{*}{ WeIISAT } & \multicolumn{4}{|c|}{$\begin{array}{c}\text { SPAW-ET Overall Nutrition } \\
\text { Euvironment }\end{array}$} & \multirow[b]{2}{*}{$\begin{array}{c}\text { p- } \\
\text { whene }\end{array}$} \\
\hline & Poo & Fai & Good & Best & \\
\hline WS Strength & - & - & $248=5.5$ & $\begin{array}{c}16.3 \pm 3 . \\
8\end{array}$ & .57 \\
\hline WS Comp & - & - & $42 . \mathrm{B}=6.7$ & $\begin{array}{c}39.0=1 \\
1.0\end{array}$ & 83 \\
\hline SVI Strength & - & - & $2 \mathrm{~B} 5=4.1$ & $19=64$ & 40 \\
\hline SMI Comp & - & - & $42.0=4.9$ & $40=6.7$ & 92 \\
\hline WE Strength & - & - & $37-1=7.1$ & $\begin{array}{c}33.7 \pm 4 \\
7\end{array}$ & 86 \\
\hline NE ComI & - & - & $\begin{array}{c}\text { B.1. } 0=12 \\
7\end{array}$ & $\begin{array}{c}77.9=6 \\
5\end{array}$ & 86 \\
\hline Overall Strength & - & - & $27.0=4.5$ & $\begin{array}{c}17.3=1 \\
7\end{array}$ & -43 \\
\hline $\begin{array}{l}\text { Overall } \\
\text { Coungrehensiveness: }\end{array}$ & - & - & $47 \mathrm{~B}=5.0$ & $41=3.5$ & .62 \\
\hline
\end{tabular}

NS - mutrition standards for comperitive foods and beverages: SM- school meale; XE - nutrition

education- Comp - comprehensiveness

\section{Discussion}

The school nutrition environment has the potential to shape and influence lifelong healthy eating behaviors. Policies should be written and implemented to create a nutrition environment that support students in making healthy choices. Although strides have been made in writing district-level SWPs, it remains unclear if and how those policies are being implemented. As such, in this study, we examined the association between overall quality (strength and comprehensiveness) of written school nutrition wellness policies and the observed physical, situational and policy nutrition environments within Midwestern elementary schools. There were few significant correlations between observed nutrition areas of interest and written SWP nutrition section scores, and no differences in written SWP nutrition section scores across categorical scores of the observed nutrition environment or areas of interest. There was a significant positive correlation between strength of written nutrition standards for competitive foods and beverages and garden features area of interest. SWP nutrition standards for competitive foods and beverages address compliance with the USDA nutrition standards for all foods during the regular and extended school day, after school programming and clubs and nutrition standards for all foods and beverages served to students while attending before/aftercare on school grounds. The individual criteria that make up garden features area of interest include a variety of indoor and outdoor features such as in-ground gardens, raised beds, containers, and/or whether landscape features exist. Garden features also include a space where edible plants can be grown and harvested across seasons and/or garden space(s)/features used to grow a variety of edible plants such as vegetables, fruits, legumes, greens and herbs. The mean score for garden elements was a $2(0-50 \%)$ and $96 \%$ were poor while $4 \%$ was fair. Nutrition standards for competitive food and beverages relate to the sale or service of foods outside of USDA school meals. Fruits and vegetables from school gardens can be incorporated into this category which may have led to the positive correlation seen although garden participation and overall garden scores were poor amongst schools.

There was a significant negative correlation between written SWP nutrition education comprehensiveness and school meals area of interest. For school meals, majority of the scores fell within best category (96\%) but had low wellness policy strength and comprehensive scores. 
SWP nutrition education address' standard based nutrition curriculum, health education curriculum, or other curriculum that includes nutrition and assessing whether elementary, middle or high school students receive nutrition education. Links between nutrition education and the school food environment, nutrition education for behavior skills and nutrition education that is sequential and comprehensive also make up SWP nutrition education. School meals area of interest address breakfast and lunch service, whether school meal programs meet or exceed USDA and/or state standards for reimbursable meals, whether school meal programs participate in farm-to-school activities that integrate local agriculture products into school meals and also whether lunch is served after recess, but between 11-1. Other categories addressed under school meals area of interest include whether meals prevent overt identification of students who are eligible for free and reduced-price school meals and makes every effort to eliminate social stigma. Whether menu items represent the cultural diversity of the population and available in languages student primarily speak, information about the nutritional content of meals, annual training covering food safety and training related to basic nutrition and healthy eating concepts being aligned with dietary guidelines is completed by the food service manager and staff who prepares and serves meals is also incorporated into school meals area of interest. The current school meals program could possibly have a role to play in the results seen in this study. In the observed nutrition environment, school meal scores included standards for reimbursable meals which the USDA provides to all schools participating in the school meals program. Currently, school meals must meet the Dietary Guidelines for Americans with fruits, vegetables, whole-grains and protein although the decisions about what specific foods to serve and how to prepare meals are made by the local school food authorities (Vaudrin 2018).

There was a lack of similarities in SWP scores across the different categories of SPAN-ET scores. Higher written school SWP scores were expected in the better categories of SPAN-ET scores but not what was seen. This could possibly be due to what was being evaluated. The components of WellSAT did not directly align with the components of SPAN-ET and written wellness policies in this study often did not reflect school-reported nutrition policies and practices which is evident by there being no significant relationship between overall strength and comprehensiveness of SWPs and SPAN-ET nutrition and wellness policy area of interest. Written SWP scores do not fully capture the physical, situational and policy environment; highest quality SWPs should be aligned with evidence that contributes to the healthiest school environments.

Higher SPAN-ET scores could be achieved if schools avoid using food as a reward for good behavior or good grades. With regards to food and beverage habits and food and beverage practice criteria, higher scores could be seen if the food and beverages available at school stores, carts, vending machines, fundraisers, birthday parties, classroom reward parties and classroom treats/rewards met smart snack regulations. Majority of schools, all but one, scored within the poor category for garden features; there is room for improvement with school garden implementation. School gardens with edible fruits and vegetables have the potential to teach students about their true source of food and teach students valuable gardening and agriculture concepts and skills that can be integrated into subjects such as health education, science and art and also improve the school nutrition environment (Cairns 2017).

In the health and nutrition education criteria, nutrition education policies, whether a health educator was hired by the school district and minutes of annual health education were assessed. Poor scores indicated that schools did not meet the recommended 400 minutes of annual nutrition education time and had no health educator. Due to lack of funds and resources, many schools had no nutrition educator hired by the school district. Physical education teachers often incorporated nutrition education into their classes or the school nurse or counsellor provided weekly or monthly nutrition topics or education. This finding is similar to that of Snelling et al. who noted that schools have been successful in incorporating nutrition topics or lessons, but more resources are needed for schools to achieve the needed minutes of health and physical education (Hoxie-Setterstrom 2011).

Strength and comprehensiveness of wellness policies and wellness policy implementation varied widely amongst schools with the majority of schools falling in the poor and fair category for overall strength and comprehensiveness. Higher WellSAT 2.0 scores could be attained by ensuring policies are clear and void of loopholes that may weaken the enforcement (Uconn 2018). Specific language should be used to describe policy items; strong language such as will, must, have to, require, total, comply and enforce should also be used to indicate that action or regulation is required (Uconn 2018). This finding was similar to Budd et al. who found that the quality of wellness policy implementation varies among schools in the United States with challenges to implementation including lack of time or coordination of the policy team, lack of monetary resources, no consequences for non-compliance, lack of training, being unsure about how to proceed and lack of leadership (Budd 2012). Understanding how schools are complying with SWPs is important in determining where additional resources or support is needed in order to support school-wide adoption of wellness policies and ensuring best practices for a healthy nutrition environment. Facilitating factors such as grants and barriers such as lack of clarity about responsibility for policy enforcement are important factors that determine whether policy implementation will be successful. 
Funding and time constraints represent important obstacles to the successful adoption, implementation, and evaluation of SWPs that will require systemic change in order to address (Agron 2010, Harriger 2014, Lucarelli 2015). Gaining the support of key stakeholders is also critical for successful policy implementation (Lucarelli 2015).

This study is not without limitations. Majority of schools visited in this study were located in rural counties. Having equal parts rural, metro and non-metro schools and being able to observe the scores would make this study more generalizable. These rural schools also had small school population sizes which may not be the case in more populated states with multiple inner-city schools. Despite these limitations, there are very few studies that address comprehensiveness and strength of policy implementation and its association with the nutrition environment. This study serves to fill the gap of whether strength and comprehensive nutrition policies have an impact on nutrition environment.

\section{Conclusion}

Assessing whether strength and comprehensiveness of SWPs is associated with better nutrition environment provides information that has the potential to shape policy development and the school nutrition environment. Lack of funds, resources and time constraint could potentially play a role in policy development and implementation and in turn the nutrition environment. Understanding how schools are creating and implementing SWPs is important in determining where additional resources or support is needed in order to support school-wide adoption of wellness policies. Understanding how schools are creating and implementing SWPs is also important for improving the school nutrition environment, along with ensuring policies align with what we know about healthy eating nutrition environment within schools.

\section{Implications for School Health}

The information and data presented in this study have the potential to shape policy development and the school nutrition environment. It is mandatory for elementary schools to have a written SWP, but this study highlights how strength and comprehensiveness of written SWPs affects the school nutrition environment. This study further highlights the areas of interest within the physical, situational and policy nutrition environment where schools are doing poor, fair, good or performing at best practice and where there is room for improvement in policy implementation. Possible reasons why schools may be scoring the way they did are also highlighted in this study. A healthy school nutrition environment can make it easier for students to make healthy choices; assessing the school nutrition environment identifies opportunities for improvement and begins a planning process for making schools even healthier. This study provides valuable information on whether SWPs support creating a healthy nutrition environment.

\section{References}

United States Department of Agriculture Food and Nutrition Services. Local School Wellness Policy. https://www.fns.usda.gov/tn/local-school-wellness-policy. November 2017. Accessed February 2nd 2018.

Methos J, Nanney MS. (2007). The strength of school wellness policies: one state's experience. J School Health.77(7):367-372.

Chan E, Ross V(2014). Narrative understandings of a school policy: intersecting student, teacher, parent and administrator perspectives. J Curriculum Stud.46(5),656-675.

Hoxie-Setterstrom G, Hoglund B. (2011). School wellness policies: opportunities for change. J Sch Nurs. 2011;27(5):330-339.

Cox M, Ennett S, Ringwalt C, Hanley S, Bowling J. (2016). Strength and Comprehensiveness of School Wellness Policies in Southeastern US School Districts. J School Health.86(9),631-637

Lucarelli J, Alaimo K, Liu H, et al. (2015). Little Association Between Wellness Policies and School-Reported Nutrition Practices. Health Promot Pract.16(2), 193-201.

Meendering J, Kranz E, Shafrath T, McCormack LA (2016). Bigger $\neq$ Better: The comprehensiveness and strength of school wellness policies varies by school district size. J Sch Health. 86,653-659.

Holland J, Green J, Alexander L, Phillips M (2016). School Health Policies: Evidenced-based Programs for Policy Implementation. Journal Of Policy Practice.15(4),314-332.

Phillips MM, Raczynski JM, Goodell M, Perez AG. (2012). Creating and using index scores in the analysis of school policy implementation and impact. J School Health.82(6),253-261.

Snelling A, Belson S, Katz N, et al (2017). Measuring the Implementation of a School Wellness Policy. J School Health. 87(10),760-768.

Cox M, Ennett S, Ringwalt C, Hanley S, Bowling J (2016). Strength and Comprehensiveness of School Wellness Policies in Southeastern US School Districts. J School Health. 86(9),631-637. 
Craven T, Young T, Markenson D, Gibson C (2017). School Wellness Policy Development. J Acad Nutr Diet.117,A48.

Kelsey M, Zaepfel A, Bjornstad P, Nadeau K. (2014). Age-Related Consequences of Childhood Obesity. Gerontology.60(3),222-228.

Price C, Cohen D, Pribis P, Cerami J (2017). Nutrition Education and Body Mass Index in Grades K-12: A Systematic Review. J School Health.87(9),715-720

Rubio D, Lane H, Lopes M, et al (2017). School wellness team best practices to promote wellness policy implementation. Preventive Medicine.101,34-37

Oregon State University. School Physical Activity \& Nutrition Environment Tool. (2018) http://extension.oregonstate.edu/growhkc/tools/span-et

UCONN Rudd Center Food For Policy \& Obesity. (2018).Wellness School Assessment Tool.http://uconnruddcenter.org/

StataCorp. 2017. Stata Statistical Software: Release 15. College Station, TX: StataCorp LLC

Vaudrin N, Lloyd K, Yedidia M, Todd M, Ohri-Vachaspati P. (2018). Impact of the 2010 US Healthy, Hunger-Free Kids Act on School Breakfast and Lunch Participation Rates Between 2008 and 2015. Am J Public Health.108(1),84-86

Cairns K (2017). Connecting to food: cultivating children in the school garden. Children's Geographies.15(3),304-318.

Sánchez V, Hale R, Halasan C, et al (2014). School Wellness Policy Implementation: Insights and Recommendations From Two Rural School Districts. Health Promot Pract. 15(3),340-348.

Budd E, Schwarz C, Yount B et al (2012). Factors Influencing the Implementation of School Wellness Policies in the United States, 2009. Prev Chronic Dis.9(118), 1-9.

Agron P, Berends V, Ellis K, Gonzalez M (2010). School Wellness Policies: Perceptions, Barriers, and Needs Among School Leaders and Wellness Advocates. J School Health. 80(11),527-535.

Harriger D, Lu W, McKyer E, Pruitt B, Goodson P (2014). Assessment of School Wellness Policies Implementation by Benchmarking Against Diffusion of Innovation Framework. J School Health. 84(4),275-283

Lucarelli J, Alaimo K, Liu H, et al. (2015). Little Association Between Wellness Policies and School-Reported Nutrition Practices. Health Promot Pract.16(2),193-201 